\title{
Alterations in PTEN, MDM2, TP53 and AR protein and gene expression are associated with canine prostate carcinogenesis
}

\author{
Luis Gabriel Rivera-Calderón ${ }^{\mathrm{a}, 1}$, Carlos Eduardo Fonseca-Alves ${ }^{\mathrm{b}, 1}$, Priscila Emiko Kobayashi ${ }^{\mathrm{b}}$, \\ Marcio Carvalho ${ }^{\mathrm{b}}$, Sandra Aparecida Drigo ${ }^{\mathrm{c}}$, Rosemeri de Oliveira Vasconcelos ${ }^{\mathrm{a}}$, Renée Laufer-Amorim ${ }^{\mathrm{a}, \mathrm{b}, *}$ \\ a Faculdade de Ciências Agronômicas, Univ. Estadual Paulista - UNESP, Jaboticabal, SP, Brazil \\ ${ }^{\mathrm{b}}$ Department of Veterinary Clinic, School of Veterinary Medicine and Animal Science, Univ. Estadual Paulista - UNESP, Botucatu, SP, Brazil \\ c Department of Urology, Botucatu Medical School - FMB, Univ. Estadual Paulista - UNESP, Botucatu, SP, Brazil
}

\section{A R T I C L E I N F O}

\section{Article history:}

Received 25 August 2015

Received in revised form 23 February 2016

Accepted 7 March 2016

\section{Keywords:}

Dog

Prostatic disease

Formalin-fixed tissue

Immunohistochemistry

Gene expression

\begin{abstract}
A B S T R A C T
The PTEN, AR, MDM2 and p53 protein network plays a central role in the development of many human cancers, thus eliciting the development of targeted cancer therapeutics. Dogs spontaneously develop tumours, and they are considered a good model for comparative oncology initiatives. Due to the limited information on these proteins in canine tumours, this study aimed to investigate gene and protein alterations in PTEN, AR, MDM2 and p53 in canine prostate cancer (PC). Protein expression was evaluated by immunohistochemistry (15 normal, 22 proliferative inflammatory atrophy (PIA) and 19 PC samples) and Western blotting (2 normal prostate tissue, 2 BPH, 2 PIA samples and 2 PC samples) and gene expression by RT-qPCR (10 normal, 10 PIA and 15 PC samples) of formalin-fixed tissue. We identified nuclear and cytoplasmic expression of PTEN and p53 in all samples, with only nuclear staining found for MDM2 and AR. Our results revealed high expression of MDM2 in PC and PIA samples compared to normal samples, whereas PTEN, P53 and AR expression was down-regulated in PC compared to normal tissue. All tumour samples $(n=19)$ showed loss of nuclear PTEN expression, and all cancer mimickers showed positive nuclear staining. Therefore, nuclear PTEN staining could be a good diagnostic marker for differentiating between malignant lesions and mimickers. Canine prostate carcinogenesis involves increased expression of MDM2 in association with decreased expression of PTEN, p53 and AR, such as occurs in hormone refractory PC in men. Thus, dogs may be an important model for studying advanced stage PC.
\end{abstract}

(c) 2016 Elsevier Ltd. All rights reserved.

\section{Introduction}

Dogs are commonly affected by proliferative prostatic lesions that are related to advanced age and changes in the levels of androgen hormones (Fonseca-Alves et al., 2013). Dogs are the only nonprimate species that spontaneously and naturally develops prostate carcinoma (PC) (Palmieri et al., 2014). Dogs and humans have some similarities in the clinical and pathologic aspects of PC, including the presence of preneoplastic lesions and bone metastasis (Leroy et al., 2006). In fact, dogs are indicated as a potential animal model for studying the biological behaviour of various proliferative prostatic diseases that affect humans (Palmieri et al., 2014).

There is evidence that inflammation contributes to prostate carcinogenesis (Palapattu et al., 2004), causing repeated damage to the genome and resulting in increased cell proliferation (Montironi et al., 2007).

\footnotetext{
* Corresponding author at: Department of Veterinary Clinic, School of Veterinary Medicine and Animal Science, Univ. Estadual Paulista, Distrito de Rubião Jr. s/n, 18618970, Brazil.

E-mail address: renee@fmvz.unesp.br (R. Laufer-Amorim).

1 These authors contributed equally to this work.
}

Prostatic inflammatory atrophy (PIA) is a lesion that may have an inflammatory origin, and PIA has been identified in both humans and dogs (De Marzo et al., 2007; Fonseca-Alves et al., 2014; Palmieri et al., 2014; Fonseca-Alves et al., 2015). De Marzo et al. (2007) proposed that areas of PIA are direct precursors of prostatic intraepithelial neoplasia (PIN) or PC.

In humans, the risk of PC increases with the presence of mutated genes, such as MDM2 and AR (Rubin and De Marzo, 2004), and tumour suppressor genes including phosphatase and tensin homolog (PTEN) and TP53 play an important role in the origin of this neoplasia (Uzoh et al., 2009; Wozney and Antonarakis, 2014). PTEN acts as an antagonist of the Phosphatidylinositol-3 (PI3K) signalling pathway through the regulation of murine double minute 2 (MDM2) activity (Mayo and Donner, 2002). Under normal conditions, MDM2 inhibits the transcriptional activity of p53 and regulates cell cycle, DNA repair, senescence, apoptosis and angiogenesis (Pant and Lozano, 2014). The perturbation of these processes allows mutations to accumulate in a cell, which can be transferred to future generations, thereby increasing the risk of developing cancer (Barbieri and Tomlins, 2015).

MDM2 is overexpressed in various canine neoplasias, including osteosarcomas, mast cell tumours, soft tissue sarcomas and hepatoid gland 
tumours (Nakano et al., 2005; Wu et al., 2006). In human PC, MDM2 overexpression is correlated with a higher risk of metastasis, a reduced survival time for patients and increased hormonal refraction or resistance to antineoplastic agents (Khor et al., 2009; Yu et al., 2014). The close association between the PTEN-MDM2-p53 pathway and the androgen receptor (AR) enables normal prostate function (Carver et al., 2011; Wang et al., 2011). PTEN controls AR levels and is required for the maturation and differentiation of prostatic tissue (Nicholson and Ricke, 2011). However, in human PC, mutated PTEN confers a favourable environment for the activation of certain antiapoptotic proteins, such as BCL-2 and BCL-XL, which have been implicated in the conversion of androgen-dependent PC to androgenrefractory PC (Sun et al., 2008).

In a previous study performed by our research group, we identified numerous copy number abnormalities in fourteen canine PC samples using comparative genomic hybridization (CGH), including copy number losses in the TP53, PTEN and AR genes and copy number gains in the MDM2 gene (unpublished data). These previous results provided strong evidence that the PTEN-MDM2-p53 network is associated with the development of PC in dogs, but no previous studies have evaluated the protein or gene expression of factors in this network in canine PC.

The objectives of this study were to evaluate PTEN-MDM2-p53 and AR gene and protein expression in proliferative canine prostatic lesions and to compare these data with findings reported in humans.

\section{Materials and methods}

\subsection{Samples}

A total of 56 formalin-fixed, paraffin-embedded (FFPE) prostate tissues from dogs (aged 1-15 years, of pure or mixed breeds) were selected from the archives of the Veterinary Pathology Service, São Paulo State University (UNESP), Botucatu, SP, Brazil. The samples were collected during necropsy on animals that had an interval between death and necropsy of $<24 \mathrm{~h}$. All owners agreed to the necropsy.

Haematoxylin and eosin (H\&E) blocks were cut for histopathological diagnosis, which was performed by three pathologists using a multihead microscope. The samples were classified as normal prostate, PIA or PC according to Palmieri et al. (2014) as part of the histopathological evaluation. From these slides, the most representative area for each diagnosis was selected and used to construct a TMA slide, as described by Bubendorf et al. (2001). The TMA slide consisted of 22 PIA, 19 PC and 15 normal prostate samples. Each lesion was collected from a different animal, and the sample tissues were placed on a TMA block in triplicate. After the TMA was constructed, the first and last slide sections were stained with H\&E as an internal control for the TMA lesions.

We extracted mRNA from 35 FFPE samples, which were obtained from the archive (10 normal prostate, 10 PIA and 15 PC samples), not from the same animals used to generate the TMA. We used eight frozen prostatic tissue to western blotting analysis ( 2 normal prostate tissue, 2 $\mathrm{BPH}, 2$ PIA samples and 2 PC samples).

\subsection{Real-time reverse transcription $P C R$}

The FFPE samples were manually macrodissected with needles (16 and 18 gauge) according to the procedure described by Pires et al. (2006), which enabled RNA extraction from only parts of tissue that met the pathological conditions under study. The processes of deparaffinization, protease and nuclease digestion, and nucleic acid isolation and purification were performed using a commercial RecoverAll ${ }^{\mathrm{TM}}$ Total Nucleic Acid Kit (Ambion, Life Technologies, MA, USA) according to the manufacturer's instructions. The RNA concentration was determined with a spectrophotometer (NanoDrop ${ }^{\mathrm{TM}}$, ND-8000, Thermo Scientific, MA, USA), while the RNA integrity was evaluated with a Bioanalyzer 2100 and an Agilent RNA 6000 Nano Kit (Agilent Technologies, CA, USA).
cDNA was synthesized in a final volume of $20 \mu \mathrm{L}$, and each reaction contained $1 \mu \mathrm{g}$ of total RNA treated with DNAse I (Life Technologies, Rockville, MD, USA), 200 U of SuperScript III reverse transcriptase (Life Technologies), $4 \mu \mathrm{L}$ of $5 X$ SuperScript First-Strand Buffer, $1 \mu \mathrm{L}$ of each dNTP at $10 \mathrm{mM}$ (Life Technologies), $1 \mu \mathrm{L}$ of Oligo-(dT) $18(500 \mathrm{ng} / \mu \mathrm{L})$ (Life Technologies), $1 \mu \mathrm{L}$ of random hexamers ( $100 \mathrm{ng} / \mu \mathrm{L}$ ) (Life Technologies), and $1 \mu \mathrm{L}$ of $0.1 \mathrm{M}$ DTT (Life Technologies). Reverse transcription was performed for $60 \mathrm{~min}$ at $50^{\circ} \mathrm{C}$, and the enzyme was subsequently inactivated for $15 \mathrm{~min}$ at $70{ }^{\circ} \mathrm{C}$. cDNA was stored at $-80^{\circ} \mathrm{C}$.

RT-qPCR for PTEN, MDM2, TP53, AR and the reference gene (Table 1) was conducted in a total volume of $10 \mu \mathrm{L}$ containing Power SYBR Green PCR Master Mix (Applied Biosystems; Foster City, CA, USA), $1 \mu \mathrm{L}$ of cDNA (1:10) and $0.3 \mu \mathrm{L}$ of each primer. The reactions were performed in triplicate in 384-well plates using QuantStudio 12K Flex Thermal Cycler equipment (Applied Biosystems; Foster City, CA, USA). A dissociation curve was included in all experiments to determine the PCR product specificity. The most stable reference gene (HPRT) was chosen using geNorm software (Vandesompele et al., 2002) from a group of three genes (GAPDH, HPRT, and RPL8). Relative gene expression was quantified using the $2^{-\Delta \Delta C T}$ method (Livak and Schmittgen, 2001).

\subsection{Western blotting}

The blots were blocked with $3 \%$ bovine serum albumin in TBS-T (10 mM Tris- $\mathrm{HCl}$ pH 7.5, $150 \mathrm{mM} \mathrm{NaCl}, 0.1 \%$ Tween-20) for $2 \mathrm{~h}$ and incubated overnight with the respective primary antibodies (PTEN - 1:1000; P53-1:500; AR - 1:250 and MDM2-1:1000). We used the goat anti- $\beta$-actin antibody (1:1000; sc-1615, Santa Cruz Biotechnology, Santa Cruz, CA, USA) such as control. After incubation with the corresponding horseradish peroxidase-conjugated secondary antibodies, the blots were detected by means of chemiluminescence (Amersham ECL Select Western Blotting Detection Reagent, GE Helthcare). The protein expression was quantified by densitometric analysis of the bands and was expressed as integrated optical density (IOD). The protein expression was normalized to the $\beta$-actin values. Normalized data are expressed as the means \pm SD.

\subsection{Immunohistochemistry}

The primary antibodies employed were validated in our laboratory for use in dogs in Western blot analysis with different canine prostatic tissues. The slides were deparaffinized in xylene and rehydrated in graded ethanol, and immunohistochemical staining was performed using a polymer system. Antigen retrieval was performed with citrate buffer ( $\mathrm{pH}$ 6.0) in a pressure cooker (Pascal; Dako, Carpinteria, CA, USA), and no antigen retrieval was necessary for the PTEN antibody. Endogenous peroxidase activity was inhibited with $8 \%$ hydrogen peroxide in methanol for $20 \mathrm{~min}$, and non-specific binding sites were blocked with $3 \%$ skim milk for $60 \mathrm{~min}$ at room temperature. The antibodies and dilutions are described in Table 2. A polymer system (Advance, Dako, Carpinteria, CA, USA) was applied as the secondary antibody. Peroxidase activity was visualized with 3,3'-diaminobenzidine tetrahydrochloride (DAB) (DAB +, Dako, Carpinteria, CA, USA), and the slides were counterstained with Harris haematoxylin. Negative controls were performed for all antibodies by replacing the primary antibody with immunoglobulin from the species in which the primary antibody was

Table 1

Primers sequences used for gene expression.

\begin{tabular}{lll}
\hline Gene & Foward & Reverse \\
\hline PTEN & 5'-CGACGGGAAGACAAGTTCATG-3' & 5'-TCACCGCACACAGGCAAT-3' \\
MDM2 & 5'-GGGCCCCTTCGTGAGAATTG-3' & 5'-GGTGTGGCTTTCTCAGGGATT-3' \\
TP53 & 5'-GAACGCTGCTCTGACAGTAGTGA-3' & 5'-CCCGCAAATTCCTTCCA-3' \\
AR & 5'-CGCCCTGACCTGGTTT-3' & 5'-GGCTGTACATCCGGGACTTG-3 \\
HPRT & 5'-AGCTTGCTGGTGAAAAGGAC-3' & 5'-TTATAGTCAAGGGCATATCC-3'
\end{tabular}


Table 2

Primary antibodies used.

\begin{tabular}{|c|c|c|c|c|}
\hline Antibodies & Manufacturer & Clone & Dilution & Incubation \\
\hline Polyclonal rabbit anti-PTEN & Bioss, Massachusetts, USA. & Bs-0686R & $1: 500$ & ON \\
\hline Polyclonal rabbit anti-MDM2 & Abcam, Cambridge, UK & ab38618 & $1: 50$ & ON \\
\hline Monoclonal mouse anti-p53 & & B-P3 & $1: 50$ & $\mathrm{ON}$ \\
\hline Monoclonal mouse anti-AR & Abcam, Cambridge, UK & ab77557 & $1: 100$ & ON \\
\hline
\end{tabular}

ON: overnight.

produced (Dako Corp., Carpinteria, CA). The following positive control tissues and samples were used: PTEN, normal canine mammary tissue; p53, canine squamous cell carcinoma; MDM2, mast cell tumour; and AR, normal canine prostatic tissue.

The immunohistochemistry results were evaluated according to the percentage of positive cells ( 0 - absence of staining; score $1: 1$ to $25 \%$ of positive cells; score 2: 26 to $50 \%$ of positive cells; score 3: 51 to $75 \%$ of positive cells and score 4 : more than $76 \%$ of positive cells).

\subsection{Statistical analysis}

Statistical analysis was performed using GraphPad Prism 5 v.5.0 (GraphPad Software Inc., La Jolla, CA). The Kruskal-Wallis or MannWhitney $U$ test was applied to compare the levels of PTEN, MDM2, TP53 and AR transcripts among the samples. Due to the low number of PC samples subjected to qRT-PCR, we used measures of central tendency and quartiles for analysis. The Chi-square test or Fisher's exact test was used to determine the association between the categorical variables for immunochemistry. Statistical significance was set at $p<0.05$.

\section{Results}

\subsection{Histology}

Among the samples, we identified 15 normal prostate tissue samples, 22 samples with PIA, and 19 with carcinoma. Ten tumours displayed an acinar pattern (10/19), four tumours showed cribriform pattern (4/19), three showed mixed pattern (ductal and cribriform $3 / 19)$ and two revealed small acinar pattern (2/19). It was possible to note two cases showing lymph vessels with neoplastic emboli.

\subsection{Real-time reverse transcription $P C R$}

The median of the relative quantification (RQ) of PTEN was 3.64 in normal prostate tissue, 0.88 in PIA and 0.41 in PC (Supplementary Table 1$)$. The first quartile $\left(Q_{1}\right)$ in the normal prostate and PIA samples was 0.80 . Significant difference in PTEN levels was observed between prostatic lesions and normal prostatic tissue ( $p=0.002$; Fig. 1$)$. It was possible to identify PTEN down-expression in PC samples compared to normal samples $(p=0.0005)$ (Supplementary Table $1 ;$ Fig. 1). PIA samples showed low levels of PTEN transcripts compared to normal samples ( $p=0.0001$ ) (Supplementary Table 1; Fig. 1 ).

High MDM2 transcript means were higher in PC (1.967) and PIA (1.026) compared to normal prostate $(0.99)$ ( $p=0.0805$; Supplementary Table 1). A significant over-expression of MDM2 transcript levels was detected in PC compared to normal prostatic tissue $(p=0.0079$; Fig. 1). There was no statistical difference between PIA samples and normal prostatic tissue ( $p=0.9705)$.

A lower TP53 RQ was observed in PIA (0.942) and PC (0.604) compared to normal prostatic tissue (3.73) (Supplementary Table 1). A significant difference in TP53 levels was observed between prostatic lesions and normal prostatic tissue ( $p=0.0001$; Fig. 1$)$. Normal prostatic tissue showed a higher TP53 transcript level compared to PIA ( $p=$ $0.0001)$ and PC (0.0001) samples (Supplementary Table 1 and Fig. 1 ).

The median $A R$ transcript levels was 2.58 for normal prostatic tissue, 1.35 for PIA and 0.35 for PC. Loss of AR transcript was detected in PIA compared to normal prostate ( $p=0.0261$; Fig. 1 ). Additionally, there was a significant difference in $A R$ expression between PC and normal prostate tissue ( $p=0.0001$ ) (Supplementary Table 1 and Fig. 1 ).

\subsection{Western blotting}

We performed Western blot analysis of PTEN, MDM2, P53 and AR to validate the cross-reactivity of antibodies with canine tissue, and the results are shown in Fig. 2. MDM2 showed one specific band with $55 \mathrm{kDa}$ and p53 showed two specific bands (with $53 \mathrm{kDa}$ and $50 \mathrm{kDa}$ respectively) in all prostate samples. It was possible to identify one specific band with $98 \mathrm{kDa}$ for AR antibody and one specific band with $47 \mathrm{kDa}$ to PTEN antibody. Our western blotting results demonstrated the specificity of primary antibodies against canine tissue.

\subsection{Immunochemistry analysis}

Immunohistochemical scores for each antibody are summarized in Table 3. PTEN and p53 immunolocalization in canine prostatic tissue was both nuclear and cytoplasmic. Samples that were positive for MDM2 or AR exhibited nuclear staining. We found high scores of nuclear PTEN (scores 3 or 4), nuclear P53 (scores 3 or 4), AR (score 3 or 4 ) and low score to MDM2 (score 1 or 2 ) in normal prostatic tissue. PC samples had low scores of nuclear PTEN (score 1 or 2), nuclear p53 (score 1 ), AR ( 1 or 2 ) and high score of MDM2 (3 or 4 ).

PC had low PTEN scores (scores 1 or 2 ) with a heterogeneous distribution (Fig. 2) compared to normal prostatic $(p=0.0096)$ tissue. There was no significant difference in PTEN expression between PIA and PC, but there was a significant difference in PTEN expression among all groups ( $p=0.0147)$.

We observed nuclear MDM2 overexpression in PC compared to normal prostate ( $p=0.0001$ ) (Table 3 and Fig. 1 ). More than $85 \%$ of PC cases (17/19) had a score $\geq 3$ (Fig. 2), whereas fewer than $13 \%$ of normal prostatic tissue samples had a score $\geq 3(2 / 15)$.

p53 nuclear expression was significantly different among all groups $(p<0.0001)$. PC exhibited a loss of nuclear $\mathrm{p} 53$ expression compared to normal canine prostate (Fig. 1). Furthermore, p53 was down-regulated in PC compared to PIA ( $p<0.0001$; Fig. 1$)$.

Nuclear AR immunostaining was observed in more than $85 \%$ of normal epithelial cells (Fig. 1) (score: 4); in contrast, $81.8 \%$ of PC cases (Fig. 2) exhibited low AR protein expression (score: 1) $(p<0.0001)$. More than $65 \%$ ( $n=14$ ) of the PIA samples received a high immunostaining score (score: 4 ), and a significant difference was observed in nuclear AR expression among all groups $(p<0.0001)$.

There was a correlation between gene and protein expression in canine prostatic lesion, with PTEN, p53 and AR down expression and MDM2 over expression, in comparison to normal canine prostatic tissue.

\section{Discussion}

PTEN is a central negative regulator of the PI3K/AKT signalling cascade that influences multiple cellular functions. In dogs, PTEN is localized on chromosome 26, and PTEN expression is frequently lost in different neoplasias, including canine mammary tumours, osteosarcoma, haemangiosarcoma and melanoma (Koenig et al., 2002; Levine 

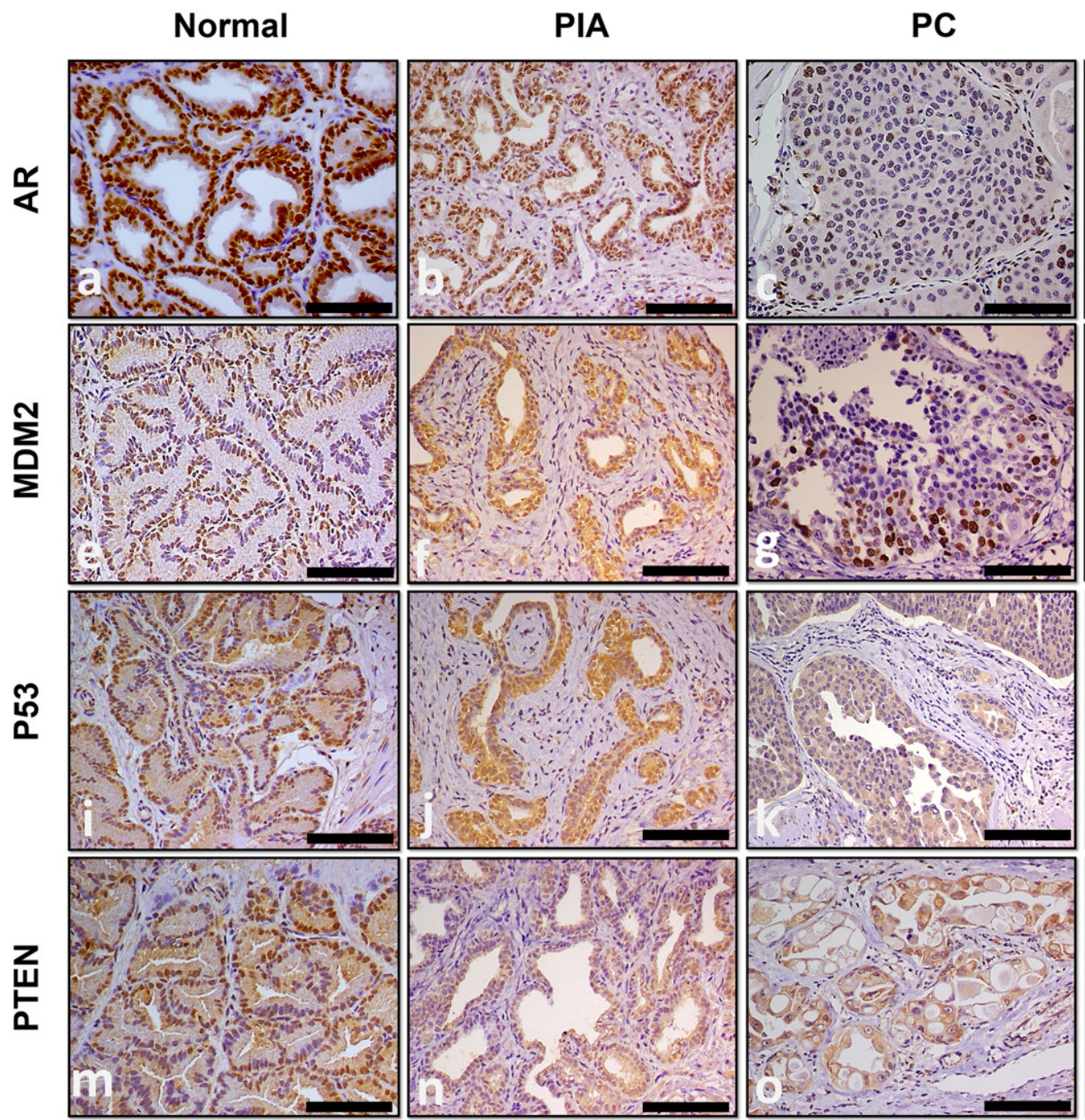

\section{Gene expression}
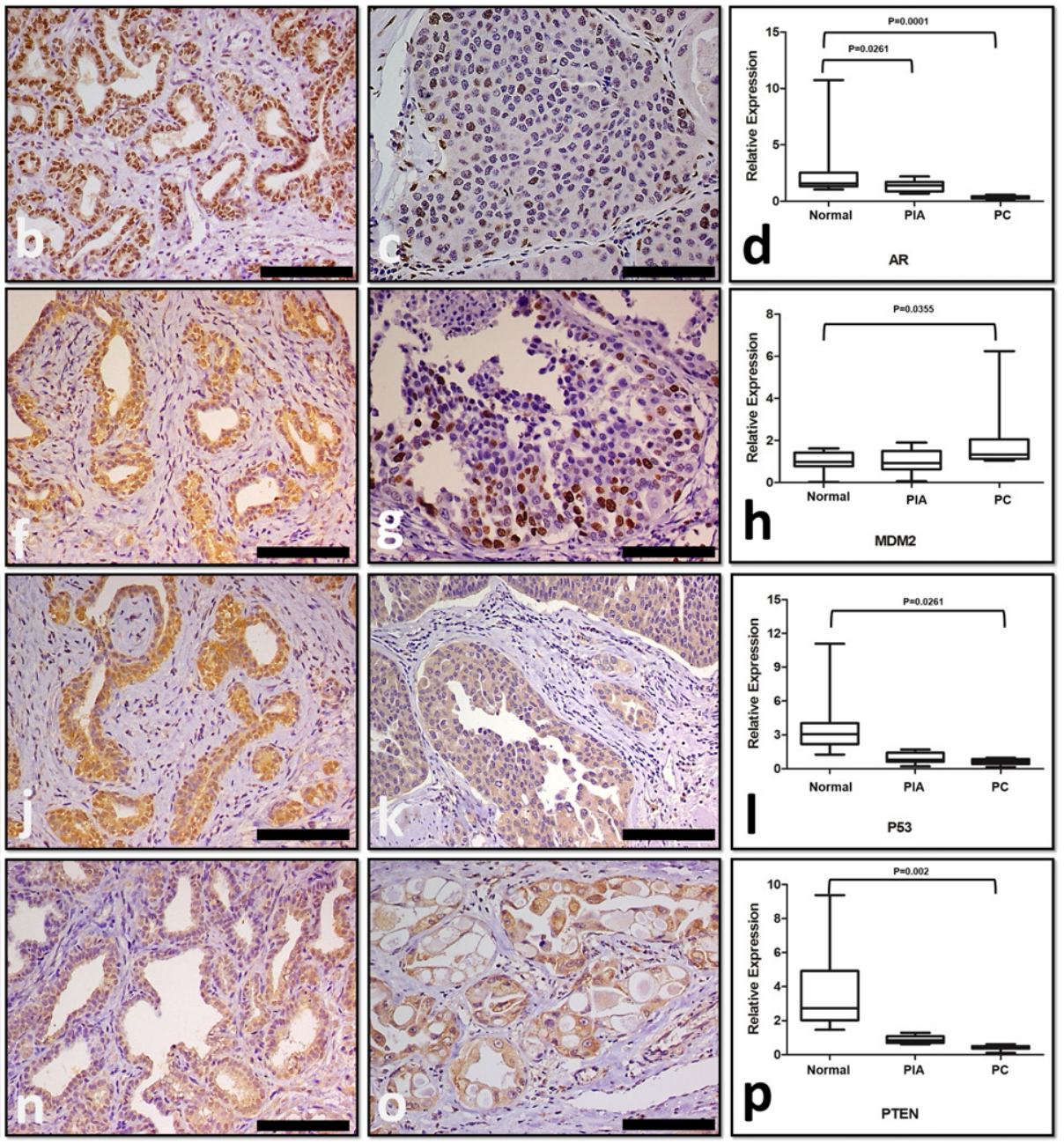

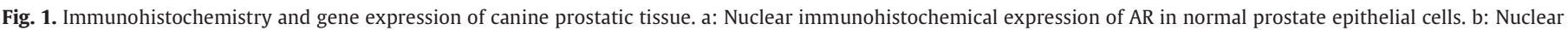

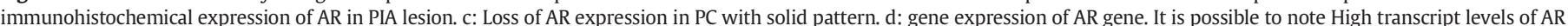

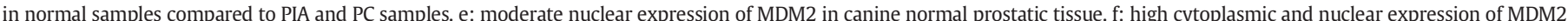

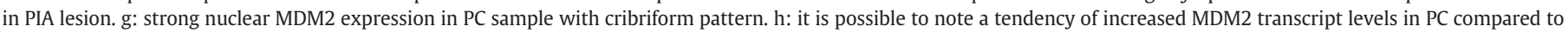

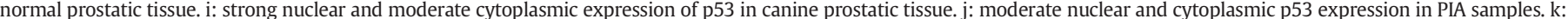

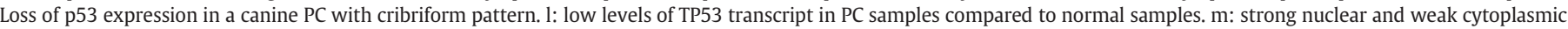

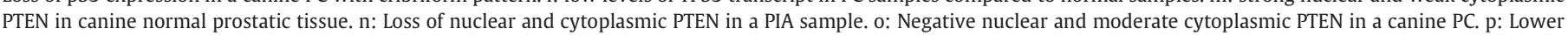
transcript levels of PTEN in PIA and PC compared to normal prostatic tissue.

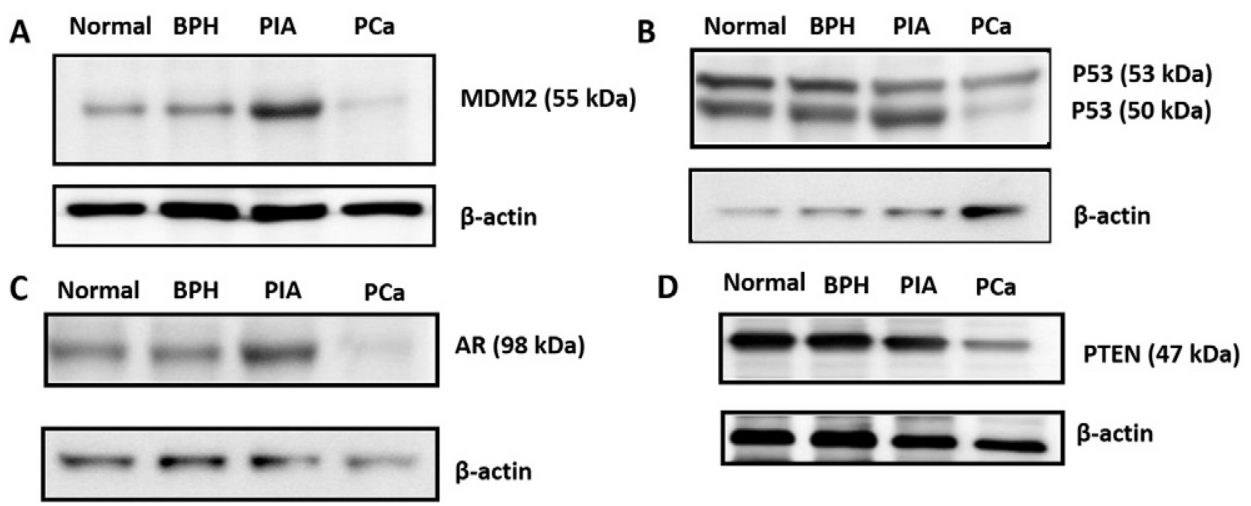

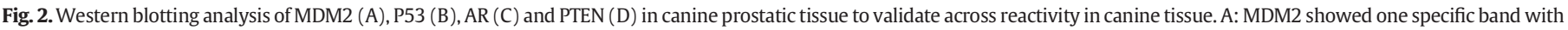

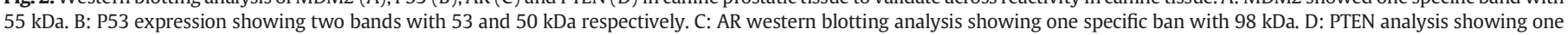
specific band with $47 \mathrm{kDa}$. 
Table 3

Immunostaining scores for PTEN, MDM2, p53 and AR of each prostatic proliferative lesions and canine prostatic normal tissue.

\begin{tabular}{|c|c|c|c|c|c|c|c|}
\hline & \multirow[t]{2}{*}{ Group } & \multirow{2}{*}{$\frac{N}{74}$} & \multicolumn{4}{|l|}{ N (\%) } & \multirow[t]{2}{*}{$\mathrm{P}$} \\
\hline & & & 1 & 2 & 3 & 4 & \\
\hline \multirow[t]{3}{*}{ PTEN $^{¥}$} & Normal & 15 & 0 & 0 & $5(33.3)$ & $10(66.6)$ & 0.0147 \\
\hline & PIA & 22 & $1(4.5)$ & $9(40.9)$ & $6(27.2)$ & $6(27.2)$ & \\
\hline & PC & 19 & $10(52.6)$ & $9(47.4)$ & 0 & 0 & \\
\hline \multirow[t]{3}{*}{ PTEN* } & Normal & 15 & $6(40)$ & $6(40)$ & $3(20)$ & 0 & $>0.05$ \\
\hline & PIA & 22 & 7 (31.8) & $7(31.8)$ & $8(36.4)$ & 0 & \\
\hline & PC & 19 & $10(52.6)$ & $6(31.5)$ & 3 (15.9) & 0 & \\
\hline \multirow[t]{3}{*}{ MDM2 } & Normal & 15 & $5(33.3)$ & $8(53.3)$ & $1(6.6)$ & $1(6.6)$ & 0.0037 \\
\hline & PIA & 22 & $3(13.6)$ & $7(31.8)$ & $6(27.2)$ & $6(27.2)$ & \\
\hline & PCa & 19 & 0 & $2(10.5)$ & $5(26.3)$ & $12(63.1)$ & \\
\hline \multirow[t]{3}{*}{ p5 $3^{¥}$} & Normal & 15 & 0 & $2(13.3)$ & $10(66.6)$ & $3(20)$ & $<0.0001$ \\
\hline & PIA & 22 & 0 & $6(27.2)$ & $6(27.2)$ & $10(45.4)$ & \\
\hline & PC & 19 & 19 (100) & 0 & 0 & 0 & \\
\hline \multirow[t]{3}{*}{ p53* } & Normal & 15 & $5(33.3)$ & $5(33.3)$ & $5(33.3)$ & 0 & $>0.05$ \\
\hline & PIA & 22 & $6(27.3)$ & $6(27.3)$ & $10(45.6)$ & 0 & \\
\hline & PC & 19 & $9(47.3)$ & $9(47.3)$ & $1(5.4)$ & 0 & \\
\hline \multirow[t]{3}{*}{ AR } & Normal & 15 & 0 & 0 & $1(6.6)$ & $14(93.3)$ & $<0.0001$ \\
\hline & PIA & 22 & 0 & $3(13.6)$ & $5(22.7)$ & $14(63.3)$ & \\
\hline & PC & 11 & $9(81.8)$ & $1(9)$ & $1(9)$ & 0 & \\
\hline
\end{tabular}

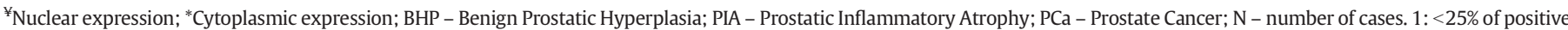
cells; 2 : $26-50 \%$ of positive cells; 3 : $51-75 \%$ of positive cells; $4:>76 \%$ of positive cells.

et al., 2002; Dickerson et al., 2005). Our previous array CGH study showed PTEN copy number loss in $21.4 \%$ (3/14) of canine PC samples, and we used immunohistochemistry and RT-qPCR to demonstrate decreased PTEN gene expression in canine PC compared to normal prostatic tissue. Qiu et al. (2008) observed loss of PTEN protein expression in canine mammary carcinomas compared to benign mammary tumours and normal canine mammary glands. As in the human carcinogenic process, PTEN down-regulation in dogs plays an important role in cancer development, and we suggest that canine PC shows loss of PTEN due to copy number losses on chromosome 26.

The loss of nuclear PTEN expression is associated with a shorter survival time in humans with PC (Ferraldeschi et al., 2015). Unfortunately, we did not have clinical information on our patients; however, we did identify nuclear PTEN expression in normal tissue and benign and preneoplastic lesions as well as loss of PTEN expression in all prostatic carcinomas. We believe that PTEN nuclear staining may be a good diagnostic marker for differentiating between malignant lesions and benign mimickers, such as in human PC. PIA lesions have an increasing association with the cytoplasmic atrophy of epithelial cells, and nucleolus and mitotic figures were evident in many cells. However, the canine prostate has no continuous basal cell layer (Leav et al., 2001; Grieco et al., 2003; Fonseca-Alves et al., 2013; Akter et al., 2015), which makes it difficult to determine whether a benign growth (cancer mimickers) has invaded the stroma (personal observation). Our results suggest that nuclear PTEN expression could be a good marker for differentiating between malignant lesions and benign mimickers.

Previously, we found copy number losses of p53 (3/14; 21.4\%) and copy number gains of MDM2 $(3 / 14 ; 21.4 \%)$ in canine PC. One case showed both loss of $p 53$ and gain of MDM2 (1/3; 33.3\%). In one case, we found concomitant loss of $p 53$ and copy number variation in PTEN, yet none of the cases showed concomitant loss of PTEN and gain of MDM2 (unpublished data). Our results suggest higher protein expression of MDM2 in PC samples and loss of nuclear p53 expression. In contrast, we found low transcript levels of MDM2 in cancer samples compared to normal and preneoplastic tissues. There is a high frequency of human head and neck carcinoma with decreased expression of MDM2 associated with p53 mutation. Indeed, decreased expression of MDM2 is associated with tumour grade and a shorter survival time in these patients (Millon et al., 2001).

Our immunohistochemical results showed loss of nuclear p53 expression and decreased cytoplasmic p53 expression in all tumours $(n=19)$ compared to normal samples. We identified lower transcript levels of $p 53$ in tumour samples compared to normal samples. We observed two specific bands (50 and $53 \mathrm{kDa}$ ) when validating the cross-reactivity of this antibody with canine tissue in the Western blot analysis. We believe that the $50 \mathrm{kDa}$ band corresponds to nuclear staining and that the $53 \mathrm{kDa}$ band corresponds to cytoplasmic staining. In the Western blot analysis, the PC samples showed a significant loss of the $50 \mathrm{kDa}$ band compared to the $53 \mathrm{kDa}$ band (Fig. 2). As identified by array CGH, loss of p53 immunoexpression was observed in PC samples compared to normal tissue samples. In human prostatic cancer cells, p53 expression is associated with resistance to docetaxel treatment: low p53 expression is associated with a good response to docetaxel, and high levels are associated with resistance to treatment (Liu et al., 2013).

We observed loss of $A R$ gene expression in PIA and PC samples compared to normal canine prostate tissue. In humans, 20-30\% of cases of castration-resistant PC have amplification of the AR gene (Linja et al., 2001; Edwards et al., 2003). Trinucleotide (CAG) repeat polymorphisms in $A R$ have been observed in human PC, but its correlation with prostate carcinogenesis remains unclear (Mao et al., 2014). We showed that fewer than $25 \%$ of the neoplastic cells in all the canine PC samples had positive nuclear AR staining, perhaps due to androgen-independence. Alterations in nuclear AR function might be observed via MDM2 overexpression or amplification; the oncoprotein MDM2 promotes the ubiquitination and proteasomal degradation of AR (Lin et al., 2002). Additionally, loss or mutation of PTEN and TP53 directly impacts the androgen-independent activation of AR (Lin et al., 2002) and the emergence of hormone-refractory PC in humans (Mao et al., 2014). Our results indicate that the described changes in the PTEN-MDM2-p53 network might affect nuclear AR function in canine PC, which is similar to the changes in this pathway that are observed in human PC (Lin et al., 2002). However, further studies on a larger number of canine prostatic lesions and clinical parameters are needed to better understand this protein network.

\section{Conclusions}

In canine carcinogenic process there is higher expression of MDM2 and down regulation of AR, p53 and PTEN, making the canine prostatic cancer a good model for independent hormonal cancer in men. Our data suggest that nuclear PTEN immunoexpression is associated with canine PC; this marker could be used to differentiate malignant lesions from benign mimickers.

Supplementary data to this article can be found online at http://dx. doi.org/10.1016/j.rvsc.2016.03.008. 


\section{Conflict of interest}

The authors declare that they have no conflicts of interest.

\section{Acknowledgements}

We thank the São Paulo Research Foundation (FAPESP) for financial support (No. 2012/16068-0).

\section{References}

Akter, S.H., Lean, F.Z., Lu, J., Grieco, V., Palmieri, C., 2015. Different growth patterns of canine prostatic carcinoma suggests different models of tumor-initiating cells. Vet Pathol. 1-8.

Barbieri, C.E., Tomlins, S.A., 2015. Reprint of: The prostate cancer genome: perspectives and potential. Urol. Oncol. 33 (2), 95-102.

Bubendorf, L., Nocito, A., Moch, H., Sauter, G., 2001. Tissue microarray (TMA) technology: miniaturized pathology archives for high-throughput in situ studies. J. Pathol. 195 (1), 72-79.

Carver, B.S., Chapinski, C., Wongvipat, J., Hieronymus, H., Chen, Y., Chandarlapaty, S., Arora, V.K., Le, C., Koutcher, J., Scher, H., Scardino, P.T., Rosen, N., Sawyers, C.L. 2011. Reciprocal feedback regulation of PI3K and androgen receptor signaling in PTEN-deficient prostate cancer. cancer Cell 19 (5), 575-586.

De Marzo, A.M., Platz, E.A., Sutcliffe, S., Xu, J., Grönberg, H., Drake, C.G., Nakai, Y., Isaacs, W.B., Nelson, W.G., 2007. Inflammation in prostate carcinogenesis. Nature 7, 256-269.

Dickerson, E.B., Thomas, R., Fosmire, S.P., Lamerato-Kozicki, A.R., Bianco, S.R., Wojcieszyn, J.W., Breen, M., Helfand, S.C., Modiano, J.F., 2005. Mutations of phosphatase and tensin homolog deleted from chromosome 10 in canine hemangiosarcoma. Vet. Pathol. 42 (5), 618-632.

Edwards, J., Krishna, N.S., Grigor, K.M., Bartlett, J.M., 2003. Androgen receptor gene amplification and protein expression in hormone refractory prostate cancer. Br. J. Cancer 89 (3), 552-556.

Ferraldeschi, R., Nava Rodrigues, D., Riisnaes, R., Miranda, S., Figueiredo, I., Rescigno, P., Ravi, P., Pezaro, C., Omlin, A., Lorente, D., Zafeiriou, Z., Mateo, J., Altavilla, A., Sideris S., Bianchini, D., Grist, E., Thway, K., Perez Lopez, R., Tunariu, N., Parker, C., Dearnaley, D., Reid, A., Attard, G., de Bono, J., 2015. PTEN protein loss and clinical outcome from castration-resistant prostate cancer treated with abiraterone acetate. Eur. Urol. 67 (4), 795-802.

Fonseca-Alves, C.E., Rodrigues, M.M., de Moura, V.M., Rogatto, S.R., Laufer-Amorim, R. 2013. Alterations of C-MYC, NKX3.1, and E-cadherin expression in canine prostate carcinogenesis. Microsc. Res. Tech. 76 (12), 1250-1256.

Fonseca-Alves, C.E., Vicente, I.S.T., Calderon, L.G.R., Justo, A.A., Rogatto, S.R., Laufer-Aorim, R., 2014. Abstract 88: Epithelial-mesenchymal transition occurs in preneoplastic and neoplastic lesions of canine prostate. Cancer Res. 74, 88.

Fonseca-Alves, C.E., Kobayashi, P.E., Rivera-Calderón, L.G., Laufer-Amorim, R., 2015. Evidence of epithelial-mesenchymal transition in canine prostate cancer metastasis. Res. Vet. Sci. 100, 176-181.

Grieco, V., Patton, V., Romussi, S., Finazzi, M., 2003. Cytokeratin and vimentin expression in normal and neoplastic canine prostate. J. Comp. Pathol. 129 (1), 78-84.

Khor, L.Y., Bae, K., Paulus, R., Al-Saleem, T., Hammond, M.E., Grignon, D.J., Che, M., Venkatesan, V., Byhardt, R.W., Rotman, M., Hanks, G.E., Sandler, H.M., Pollack, A. 2009. MDM2 and Ki-67 predict for distant metastasis and mortality in men treated with radiotherapy and androgen deprivation for prostate cancer: RTOG 92-02. J. Clin. Oncol. 27 (19), 3177-3184 (Jul 1).

Koenig, A., Bianco, S.R., Fosmire, S., Wojcieszyn, J., Modiano, J.F., 2002. Expression and significance of p53, rb, p21/waf-1, p16/ink-4a, and PTEN tumor suppressors in canine melanoma. Vet. Pathol. 39 (4), 458-472.

Leav, I., Schelling, K.H., Adams, J.Y., Merk, F.B., Alroy, J., 2001. Role of canine basal cells in postnatal prostatic development, induction of hyperplasia, and sex hormonestimulated growth; and the ductal origin of carcinoma. Prostate 48 (3), 210-224.

Leroy, B.E., Thudi, N.K., Nadella, M.N., Toribio, R.E., 2006. New bone formation and osteolysis by a metastatic, highly invasive canine prostate carcinoma xenograft. Prostate 66 (11), 1213-1222.

Levine, R.A., Forest, T., Smith, C., 2002. Tumor suppressor PTEN is mutated in canine osteosarcoma cell lines and tumors. Vet. Pathol. 39 (3), 372-378.
Lin, H.K., Wang, L., Hu, Y.C., Altuwaijri, S., Chang, C., 2002. Phosphorylation-dependent ubiquitylation and degradation of androgen receptor by akt require Mdm2 E3 ligase. EMBO J. 21 (15), 4037-4048

Linja, M.J., Savinainen, K.J., Saramäki, O.R., Tammela, T.L., Vessella, R.L., Visakorpi, T., 2001. Amplification and overexpression of androgen receptor gene in hormone-refractory prostate cancer. cancer Res. 61 (9), 3550-3555.

Liu, C., Zhu, Y., Lou, W., Nadiminty, N., Chen, X., Zhou, Q., Shi, X.B., 2013. deVere white RW, Gao AC. Functional p53 determines docetaxel sensitivity in prostate cancer cells. Prostate 73 (4), 418-427.

Livak, K.J., Schmittgen, T.D., 2001. Analysis of relative gene expression data using realtime quantitative PCR and the $2^{-\triangle \Delta C T}$ method. Methods 25, 402-408.

Mao, X., Li, J., Xu, X., Boyd, L.K., He, W., Stankiewicz, E., Kudahetti, S.C., Cao, G., Berney, D., Ren, G., Gou, X., Zhang, H., Lu, Y.J., 2014. Involvement of different mechanisms for the association of CAG repeat length polymorphism in androgen receptor gene with prostate cancer. Am. J. Cancer Res. 4 (6), 886-896.

Mayo, L.D., Donner, D.B., 2002. The PTEN, Mdm2, p53 tumor suppressor-oncoprotein network. Trends Biochem. Sci. 27 (9), 462-467.

Millon, R., Muller, D., Schultz, I., Salvi, R., Ghnassia, J.P., Frebourg, T., Wasylyk, B., Abecassis, J., 2001. Loss of MDM2 expression in human head and neck squamous cell carcinomas and clinical significance. Oral Oncol. 37 (8), 620-631.

Montironi, R., Mazzucchelli, R., Lopez-Beltran, A., Cheng, L., Scarpelli, M., 2007. Mechanisms of disease: high-grade prostatic intraepithelial neoplasia and other proposed preneoplastic lesions in the prostate. Nat. Clin. Pract. Urol. 4 (6), 321-332.

Nakano, M., Taura, Y., Inoue, M., 2005. Protein expression of Mdm2 and p53 in hyperplastic and neoplastic lesions of the canine circumanal gland. J. Comp. Pathol. 132 (1), 27-32.

Nicholson, T.M., Ricke, W.A., 2011. Androgens and estrogens in benign prostatic hyperplasia: past, present and future. Differentiation 82 (4-5), 184-199.

Palapattu, G.S. Sutcliffe, S., Bastian, P.., Platz, E.A., De Marzo, A.M., Isaacs, W.B., Nelson, W.G., 2004. Prostate carcinogenesis and inflammation: emerging insights. Carcinogenesis 26 (7), 1170-1181.

Palmieri, C., Lean, F.Z., Akter, S.H., Romussi, S., Grieco, V., 2014. A retrospective analysis of 111 canine prostatic samples: histopathological findings and classification. Res. Vet. Sci. 97, 568-573.

Pant, V., Lozano, G., 2014. Dissecting the p53-Mdm2 feedback loop in vivo: uncoupling the role in p53 stability and activity. Oncotarget 5 (5), 1149-1156.

Pires, A.R., Andreiuolo, Fda M., de Souza, S.R., 2006. TMA for all: a new method for the construction of tissue microarrays without recipient paraffin block using custombuilt needles. Diagn. Pathol. 1, 14 (25).

Qiu, C.W., Lin, D.G., Wang, J.Q., Li, C.Y., Deng, G.Z., 2008. Expression and significance of PTEN and VEGF in canine mammary gland tumours. Vet. Res. Commun. 32 (6), 463-472.

Rubin, M.A., De Marzo, A.M., 2004. Molecular genetics of human prostate cancer. Mod. Pathol. 17 (3), 380-388.

Sun, A., Tang, J., Hong, Y., Song, J., Terranova, P.F., Thrasher, J.B., Svojanovsky, S., Wang, H.G., Li, B., 2008. Androgen receptor-dependent regulation of bcl-xL expression: Implication in prostate cancer progression. Prostate 68 (4), 453-461.

Uzoh, C.C., Perks, C.M., Bahl, A., Holly, J.M., Sugiono, M., Persad, R.A., 2009. PTEN-mediated pathways and their association with treatment-resistant prostate cancer. BJ. Int. 104 (4), 556-561.

Vandesompele, J., De Preter, K., Pattyn, F., Poppe, B., Van Roy, N., De Paepe, A., Speleman, F., 2002. Accurate normalization of real-time quantitative RT-PCR data by geometric averaging of multiple internal control genes. Genome Biol. 18, 3(7).

Wang, Y., Romigh, T., He, X., Tan, M.H., Orloff, M.S., Silverman, R.H., Heston, W.D., Eng, C., 2011. Differential regulation of PTEN expression by androgen receptor in prostate and breast cancers. Oncogene 30 (42), 4327-4338.

Wozney, J.L., Antonarakis, E.S., 2014. Growth factor and signaling pathways and their relevance to prostate cancer therapeutics. Cancer Metastasis Rev. 33 (2-3), 581-594.

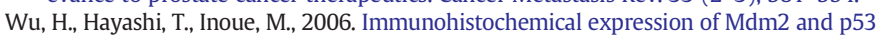
in canine cutaneous mast cell tumours. J. Vet. Med. A Physiol. Pathol. Clin. Med. 53 (2), 65-68.

Yu, Y., Zhang, Y., Guan, W., Huang, T., Kang, J., Sheng, X., Qi, J., 2014. Androgen receptor promotes the oncogenic function of overexpressed Jagged 1 in prostate cancer by enhancing cyclin B1 expression via akt phosphorylation. Mol. Cancer Res. 12 (6), 830-842. 